\title{
Asking future doctors: what support options do medical students want to cope with medical school?
}

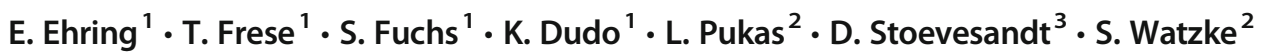

Received: 21 May 2020 / Accepted: 17 November 2020 / Published online: 11 January 2021

(C) The Author(s) 2021

\begin{abstract}
Aim Medical school is demanding, and research aimed at improving the mental health of medical students is scarce. No quantitative study about which specific measures students actually prefer to reinforce their health has been performed yet. The aim of this survey is to find out which types of support should be given to medical students according to students' own perspectives.

Subject and methods A classroom survey of medical students $(N=1108$, years $1-5)$ was carried out regarding various support options and depressive symptoms. The statistical analysis was finalized using chi-square tests, t-tests, and the KolmogorovSmirnov test.

Results The support options with the highest average scores were accessible sports classes, desire for free water/fruit during lectures, and a clear study structure. Groups to exchange experiences with, including social media groups, were favored less. Depressive symptoms in students correlated with a higher level of applicability of support options.

Conclusion Medical students require supportive study conditions. Specific subgroups of medical students could not be correlated to a particular support program. Thus, we need a support program that addresses students' wishes, not a program based on feasibility, staff interests or passions.
\end{abstract}

Keywords Mental health $\cdot$ Medical students $\cdot$ Depression $\cdot$ Support options

\section{Introduction}

"I will use treatment to help the sick according to my ability and judgment, but never with a view to injury and wrongdoing" (Hippocrates of Cos 1923). This excerpt of the Hippocratic Oath depicts an obvious fact: medical students are future doctors and hence are responsible for the wellbeing of their patients. However, students and then doctors

S. Fuchs

Stephan.Fuchs@medizin.uni-halle.de

1 Institute of General Practice and Family Medicine, Medical Faculty, Martin Luther University Halle-Wittenberg, Magdeburger Straße 8, 06112 Halle/Saale, Germany

2 Clinic for Psychiatry, Psychotherapy and Psychosomatic Medicine, Medical Hospital, Martin Luther University Halle-Wittenberg, Julius-Kühn-Straße 7, 06112 Halle/Saale, Germany

3 Student Learning Clinic "SkillsLab", Medical Faculty, Martin Luther University Halle-Wittenberg, Magdeburger Straße 12, 06112 Halle/ Saale, Germany have to stay healthy and fit themselves in order to be able to treat patients properly (Oberg and Frank 2009).

The existing surveys concerning medical students have indicated a higher stress level and higher substance abuse compared with students of other fields (Lamberti et al. 2017; Lehmann et al. 2014; Terebessy et al. 2016). Strikingly, students also often lack the appropriate coping strategies to fight the stress and demands of medical school. Less than one fifth of suffering students would actually seek help (Rotenstein et al. 2016).

Several publications assessed the implementation of methods that might help medical students to stay healthy and prevent the development of depressive symptoms (Brennan et al. 2016; Wasson et al. 2016; Kuhlmann et al. 2015). A survey of five US medical schools recently showed a positive correlation between engaging oneself in topics apart from medicine - in this case the "Exposure to Humanities" and a reduced burnout rate (Mangione et al. 2018).

Classroom surveys assessing mental health in a large number of medical students are very rare. Consequently, the intention here is to get a complete picture of views toward support 
options at a German medical school. The education of a future doctor in Germany consists of 6 years in total, starting with 2 years of preclinical studies (basic studies, including anatomy and physiology, followed by the first state exam, M1), followed by 3 years of clinical studies (basic education in medical areas, e.g., internal medicine and surgery, followed by the second state exam, M2) and a concluding year of rotations (practical year, PJ). The studies are concluded with an oral and practical colloquium at the end of the practical year (M3).

This present survey is a part of a larger survey project examining the mental health of medical students throughout the whole course of a German medical school education, including the assessment of prevalence and risk factors of mental health issues as well as students' sleep quality. This part of the larger survey intends to identify support programs that students want implemented in order to improve their health and lifestyle.

\section{Materials \& methods}

\section{Aim}

The aim of this survey is to find out which support should be given to medical students to support them and their mental health according to students' own perspectives. Results from the included Beck Depression Inventory II (BDI-II) will be correlated to the desire for support options.

\section{Design}

This was a cross-sectional, comprehensive classroom survey of medical students at a German University.

\section{Setting}

Medical School of the Martin-Luther University HalleWittenberg.

\section{Sampling \& participants}

From January 2018 to November 2018, students were examined cross-sectionally from all 5 years of the medical school of the Martin-Luther University before the second state exam. The sixth year was not evaluated since students from the sixth year complete the last part of their education in different facilities in Saxony-Anhalt and throughout Germany making a classroom survey impossible. The survey was performed as a classroom survey.

Courses with mandatory attendance were chosen in order to reach a high response rate. Students could also choose to take home the questionnaire and return it to a secure collection box in order to maintain students' privacy. Participants remained anonymous as no personal identifiers were collected. Non-participants could not be identified individually. This study emanated from a working group project that focused on different aspects of medical students' health.

\section{Instruments}

For this study, a questionnaire was created in cooperation with the Clinic of Psychiatry, Psychosomatics, and Psychotherapy that collected statistical and biometric data, including age, gender, state of origin, education, family and social background, history of personal and family illnesses, as well as substance intake, including consumption of alcohol (Terebessy et al. 2016). The Beck Depression Inventory II (BDI-II) was used to assess for depressive symptoms. Support strategies that had been assessed in other studies concluded the survey and represent the underlying data of this manuscript. Items $(N=22)$ were extracted to evaluate support options such as accessible counselors (Brennan et al. 2016) or changing the grading system into a pass/fail system (Wasson et al. 2016). The leading question was, "In order to better deal with my study-related stress, I would use the following services/wish the following services were offered." Students ranked each program on a Likert scale from 1 (entirely applicable) to 7 (does not apply at all).

\section{Data analysis \& presentation}

The analysis of the collected data was performed with IBM Statistical Package for Social Sciences (SPSS 25.0). The socio-biometric questions were presented with descriptive deviation characteristics using the mean $(\mathrm{M})$ and standard deviation (SD) where reasonable. Group differences were analyzed using chi-square and t-tests. Requested support was assessed through one-way ANOVA and calculation of relative frequencies. Data of preferred support strategies were analyzed for deviation from normal distribution. The Kolmogorov-Smirnov test showed that all items significantly deviated from normal (all $p<.001$ ). Due to skewed distribution of data, associations between depressive symptoms and requested support options were analyzed through the Spearman-rank correlation.

\section{Ethical approval}

The Ethical Committee of the Martin-Luther University HalleWittenberg approved of the survey protocol on January 18 , 2018 (2017-138).

\section{Results}

From 1235 students expected to be accessible within courses with mandatory attendance, $N=1124$ were actually present. 
Altogether, $N=1108$ students participated in the survey, resulting in an overall response rate of nearly $90 \%$. Of the surveyed students, $8 \%$ showed moderate or severe depressive symptoms according to the BDI-II, with a pre-clinical BDI-II mean of $8.84(p<0.05)$ and a clinical mean BDI-II of 7.78 $(p<0.05)$. Mild depressive symptoms were reported by $11 \%$ of the students. Precise characteristics of the survey population can be found in Table 1 .

Out of the 22 possible support options that were evaluated, the ones that were viewed as "entirely applicable" were a clear study structure $($ mean $=2.02$ points, median $=2$ ), water and fruits for free during compulsory events (mean $=2.37$, median $=2$ ), as well as a sports program that accommodates a full study schedule (mean $=2.45$, median $=2$ ). The strategies that were mostly perceived as "does not apply at all" were a social network group on Facebook (mean $=5.86$ points, median $=7$ ), groups for exchanging experiences $($ mean $=4.78$, median $=5)$, and a student health officer $($ mean $=4.73$, median $=5)$.
Table 1 Description of the sample

\begin{tabular}{|c|c|c|c|}
\hline Variable & Semester & $\mathrm{n}^{1}$ & $\%^{2}$ \\
\hline \multirow[t]{5}{*}{ Filled-in questionnaires (total $\mathrm{n}_{\text {valid }}=1108$ ) } & $1 \mathrm{st}$ & 352 & 31.8 \\
\hline & 4 th & 215 & 19.4 \\
\hline & 5 th & 231 & 20.8 \\
\hline & 9th & 154 & 13.9 \\
\hline & 10th & 156 & 14.1 \\
\hline Female students (total $\left.\mathrm{n}_{\text {valid }}=1105\right)$ & Total & 718 & 65 \\
\hline \multirow[t]{6}{*}{ Age in years $(\mathrm{M}+\mathrm{SD})$} & $1 \mathrm{st}$ & 344 & 20.9 \\
\hline & 4 th & 210 & 22.5 \\
\hline & 5 th & 225 & 23.9 \\
\hline & 9th & 153 & 25.0 \\
\hline & 10th & 154 & 25.8 \\
\hline & Total & 1086 & $23.1( \pm 3.9)$ \\
\hline \multicolumn{4}{|l|}{ Home state (total $\mathrm{n}_{\text {valid }}=1046$ ) } \\
\hline \multicolumn{2}{|l|}{ Saxony-Anhalt (area of the surveyed university) } & 179 & 17.1 \\
\hline \multicolumn{2}{|l|}{ Germany (other federal states) } & 867 & 82.9 \\
\hline \multicolumn{4}{|l|}{ Marital status (total $\mathrm{n}_{\text {valid }}=1108$ ) } \\
\hline \multicolumn{2}{|l|}{ No recent relationship } & 523 & 47.5 \\
\hline \multicolumn{2}{|l|}{ In a relationship } & 540 & 49.2 \\
\hline \multicolumn{2}{|l|}{ Married } & 36 & 3.3 \\
\hline \multicolumn{2}{|l|}{$\mathrm{BMI}(\mathrm{M}+\mathrm{SD})$} & 1083 & $22.5( \pm 3.5)$ \\
\hline \multicolumn{2}{|l|}{ Not content about own weight (total $\mathrm{n}_{\text {valid }}=1100$ ) } & 422 & 38.4 \\
\hline \multicolumn{4}{|c|}{ Professional education/studies prior to medical studies (total $n_{\text {valid }}=1103$ ) } \\
\hline \multicolumn{2}{|l|}{ None } & 714 & 64.7 \\
\hline \multicolumn{2}{|l|}{ Started but not graduated } & 112 & 10.2 \\
\hline \multicolumn{2}{|l|}{ Graduated } & 277 & 25.1 \\
\hline \multicolumn{4}{|l|}{ Use of relaxation techniques (total $\mathrm{n}_{\text {valid }}=1102$ ) } \\
\hline \multicolumn{2}{|l|}{ Yes } & 225 & 20.4 \\
\hline \multicolumn{2}{|l|}{ No } & 877 & 79.6 \\
\hline \multirow[t]{2}{*}{ BDI-II (total $\mathrm{n}_{\text {valid }}=1103$ ) } & preclinical & 564 & 8.84 \\
\hline & clinical & 539 & 7.78 \\
\hline \multicolumn{4}{|l|}{ BDI-II; range of severity (total $\mathrm{n}_{\text {valid }}=1103$ ) } \\
\hline \multicolumn{2}{|l|}{ No symptoms $(<=13)$} & 894 & $81.0 \%$ \\
\hline \multicolumn{2}{|l|}{ Mild symptoms (14-19) } & 121 & $11.0 \%$ \\
\hline \multicolumn{2}{|l|}{ Moderate symptoms (20-28) } & 62 & $5.6 \%$ \\
\hline \multicolumn{2}{|l|}{ Severe symptoms (28) } & 26 & $2.4 \%$ \\
\hline
\end{tabular}

${ }^{1} \mathrm{n}=$ absolute number of valid questionnaires; variable due to missing responses

${ }^{2}$ Unless otherwise indicated 
Table 2 Support options for students

\begin{tabular}{|c|c|c|c|c|c|c|c|}
\hline & \multicolumn{3}{|c|}{ Pre-clinical semesters } & \multicolumn{3}{|c|}{ Clinical semesters } & \multirow[t]{2}{*}{ Mann-Whitney-U; $\mathrm{p}^{\mathrm{b}}$} \\
\hline & $\mathrm{N}$ & $\mathrm{M}( \pm \mathrm{SD})$ & Median $^{\mathrm{a}}$ & $\mathrm{N}$ & $\mathrm{M}( \pm \mathrm{SD})$ & Median $^{\mathrm{a}}$ & \\
\hline Option 1: Mentoring from fellow students & 548 & $3.9( \pm 2.0)$ & 4 & 522 & $4.7( \pm 2.0)$ & 5 & 112,$191 ; \mathrm{p}<.001 *$ \\
\hline Option 2: Mentoring from university staff & 549 & $4.2( \pm 1.9)$ & 4 & 523 & $4.5( \pm 1.9)$ & 5 & $129,641.5 p=.005$ \\
\hline Option 3: Student health officer & 548 & $4.6( \pm 1.8)$ & 5 & 519 & $4.8( \pm 1.8)$ & 5 & $130,850 p=.022$ \\
\hline Option 4: Elective subject on stress and burnout & 546 & $4.4( \pm 1.9)$ & 4 & 523 & $4.6( \pm 2.0)$ & 5 & $135,832.5 p=.162$ \\
\hline Option 5: Time for volunteering & 544 & $4.3( \pm 2.1)$ & 4 & 522 & $4.3( \pm 2.1)$ & 4 & $140,196.5 p=.718$ \\
\hline Option 6: Relaxation rooms on campus & 547 & $3.6( \pm 2.0)$ & 3 & 523 & $4.0( \pm 2.1)$ & 4 & $131,256 p=.018$ \\
\hline Option 7: Exercise/sports class (at suitable times to fit your schedule) & 550 & $2.4( \pm 1.7)$ & 2 & 522 & $2.4( \pm 1.6)$ & 2 & $141,899.5 p=.735$ \\
\hline Option 8: Workshops about learning techniques & 549 & $3.9( \pm 2.0)$ & 4 & 523 & $4.1( \pm 1.9)$ & 4 & $137,346 p=.214$ \\
\hline Option 9: Lecture on stress management & 549 & $4.0( \pm 2.0)$ & 4 & 522 & $4.2( \pm 2.0)$ & 4 & $135,281.5 p=.109$ \\
\hline Option 10: Seminars and workshops on stress & 546 & $4.1( \pm 1.9)$ & 4 & 523 & $4.1( \pm 2.0)$ & 4 & $142,273.5 p=.919$ \\
\hline Option 11: Workshops/courses on autogenic training & 546 & $4.2( \pm 2.0)$ & 4 & 523 & $3.7( \pm 2.1)$ & 3 & $121,910 \mathrm{p}<.001 *$ \\
\hline Option 12: Workshops/courses on meditation & 549 & $4.0( \pm 2.1)$ & 4 & 521 & $3.7( \pm 2.1)$ & 3 & $131,222.5 \mathrm{p}=.018$ \\
\hline Option 13: Workshops/courses on relaxation exercises & 547 & $3.9( \pm 2.0)$ & 4 & 522 & $3.4( \pm 2.0)$ & 3 & $122,516.5 \mathrm{p}<.001 *$ \\
\hline Option 14: Workshops/courses on yoga & 550 & $3.9( \pm 2.1)$ & 4 & 523 & $3.6( \pm 2.1)$ & 3 & $131,973.5 \mathrm{p}=.018$ \\
\hline Option 15: Discussion groups for exchanging experiences & 547 & $4.5( \pm 1.8)$ & 5 & 522 & $4.9( \pm 1.8)$ & 5 & $125,816.5 p=.001 *$ \\
\hline Option 16: Facebook group with stress techniques and exchanges & 547 & $5.8( \pm 1.5)$ & 6 & 521 & $5.8( \pm 1.4)$ & 7 & $140,875 p=.729$ \\
\hline Option 17: Pass/fail rating system & 541 & $3.9( \pm 2.0)$ & 4 & 521 & $4.0( \pm 2.2)$ & 4 & $136,842.5 p=.407$ \\
\hline Option 18: More personal relationships with teachers/lecturers & 546 & $3.6( \pm 1.8)$ & 3 & 522 & $3.8( \pm 1.9)$ & 4 & $132,976.5 p=.055$ \\
\hline Option 19: Free water and fruit at compulsory events & 548 & $2.3( \pm 1.8)$ & 2 & 523 & $2.4( \pm 1.8)$ & 2 & $139,692 p=.447$ \\
\hline Option 20: Clear and structured organization of studies & 546 & $2.1( \pm 1.4)$ & 2 & 523 & $1.9( \pm 1.3)$ & 1 & $127,545.5 \mathrm{p}=.001 *$ \\
\hline Option 21: Change to daily study structure with fixed breaks & 547 & $3.3( \pm 1.8)$ & 3 & 523 & $3.0( \pm 1.8)$ & 3 & $131,844.5 p=.024$ \\
\hline Option 22: Low-threshold drop-in center for students with problems & 549 & $3.6( \pm 1.9)$ & 3 & 524 & $3.3( \pm 2.0)$ & 3 & $130,569.5 p=.008$ \\
\hline
\end{tabular}

${ }^{a}$ according to the Likert scale, the empirical range was 1 (entirely applicable) to 7 (does not apply at all) in all subscales

${ }^{\mathrm{b}}$ due to alpha-accumulation, Bonferroni-corrected critical $p$ value is .002 , significant differences are marked with *

Table 2 shows the mean, standard deviation, and median for each item, separately for pre-clinical and clinical terms.

Options ranked on a Likert scale from 1 (entirely applicable) to 7 (does not apply at all). Most arithmetic means fell within the range of the median with few exceptions (options 7 , 19, 20 favored most, options 3, 15, 16 favored least).

In Fig. 1, the means are presented with the values of the Likert scale divided into tertiles. The Likert scale ranged from 1 (most applicable) to 7 (least applicable). Students would answer with 1 or 2 (category 1 ) if they agreed with the stated support option and 6 or 7 (category 3 ) if they did not agree. The bar chart depicts the percentage of students that would either participate or not participate in the proposed implementations as well as the percentage of students from category 2 (points 3 to 5 ) that might benefit from the proposals. Therefore, major groups within the students become visible. From one fifth (19.6\%, clear study structure) to half of all students (47.5\%, relationships to lecturers) ranked the support options in the second tertile ( 3 to 5 ).
In Fig. 1, analysis of the evaluated options 1 to 22 (" 1 " to " 22 " in the figure) was carried out by dividing the Likert scale (range 1 to 7) into three different categories and depicted in a $100 \%$ bar chart. Category 1: ranked 1 or 2 (most applicable); Category 2: ranked 3 to 5 (middle); Category 3: ranked 6 or 7 (least applicable).

Although every option was correlated with sociodemographic data, no significant correlation was found except for the following associations: students already using relaxation techniques tend to favor courses that teach relaxation techniques (correlation $0.276 ; p<.001$ ), yoga courses $(0.342 ; p<.001)$, courses on meditation $(0.300 ; p<.001)$ and courses on autogenic training $(0.225 ; p<.001)$. The female sex represents a relevant factor as female participants are more likely to choose yoga classes $(0.299$; $p<.001)$ and relaxation techniques $(0.217 ; p<.001)$.

Correlating the results of the BDI-II to the score of each support option, some significant correlations resulted. Table 3 depicts the correlations in detail. However, a higher BDI-II score was consistently associated with a higher acceptance of support of various kinds. 


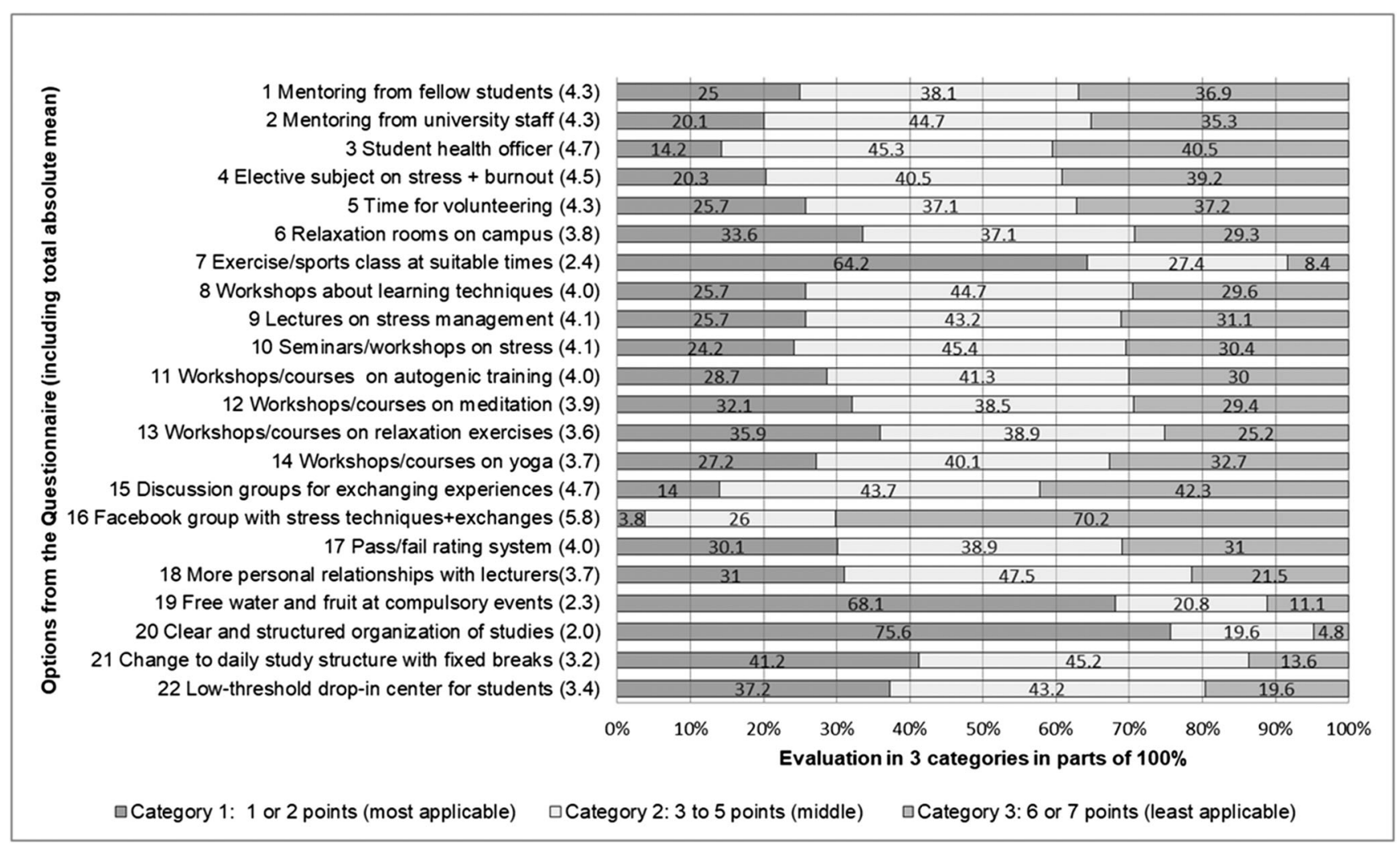

Fig. 1 Rating of support options

Table 3 Correlation between the BDI-II and support options
Option

Correlation $r$

Option 1: Mentoring from fellow students

0.015

Option 2: Mentoring from university staff

$-0.136^{* *}$

Option 3: Student health officer

$-0.150^{* *}$

Option 4: Elective subject on stress and burnout

$-0.157^{* *}$

Option 5: Time for volunteering

$-0.019$

Option 6: Relaxation rooms on campus

$-0.034$

Option 7: Exercise/sports class (at suitable times to fit your schedule)

0.045

Option 8: Workshops about learning techniques

$-0.082^{* *}$

Option 9: Lecture on stress management

$-0.160^{* * *}$

Option 10: Seminars and workshops on stress

$-0.171^{* *}$

Option 11: Workshops/courses on autogenic training

$-0.114^{* *}$

Option 12: Workshops/courses on meditation

$-0.114^{* *}$

$-0.151^{* *}$

$-0.123^{* *}$

$-0.154^{\text {** }}$

$-0.143^{* *}$

$-0.140^{* *}$

$-0.128^{* *}$

0.025

$-0.028$

$-0.156^{\text {*** }}$

$-0.189^{* *}$ 
Since a low number $(1,2$, and 3$)$ indicates high applicability of a support option and a high BDI-II score indicates more severe depressive symptoms, a negative correlation expresses a strong applicability of the support option. For example, if students report more depressive symptoms according to the BDI-II, they agreed more with the wish for a low-threshold drop-in center.

\section{Discussion}

\section{Key findings}

Whereas medical students of the local University favor a clear study structure and applicable measures such as a timetable that accommodates sports programs, options such as communication groups are considered less helpful.

\section{Context}

Medical students form a heterogeneous group coming from various regions, with different social situations and with a varying level of previous work experience, which makes it difficult to identify the necessary support options (Karay et al. 2018).

Studies examining directly the needs and desires of medical students to support their state of health are rare (Williams et al. 2015). A national survey in the US determined that medical schools implement a variety of approaches to support medical student well-being, but proper analysis and evaluation of the diverse options are required (Dyrbye et al. 2019). According to our knowledge, no other survey has been published listing different options as rated by students. Normally, studies either consist of meta-analyses (Schmidt and Hansson 2018) or the assessment of a direct intervention (Brennan et al. 2016). Qualitative collections of student suggestions exist, where a relatively small number of participants indicated options they preferred (Kötter et al. 2015). However, no further evaluation of the proposals with a larger number of students has been initiated.

Students prefer a timetable leaving time for physical exercise but are less likely to accept options where they have to present themselves in person to talk about difficulties (see Fig. 1). The support option that was viewed as the most applicable to enhance the state of health was the establishment of a clear study structure. Changing the curriculum from a teachercentered traditional setting to a student-centered approach proved appealing to medical students and effective in diminishing depressive symptoms, especially in female students (AlFaris et al. 2014). Hence, this is an option that should be explored further at medical schools.

The results from the included BDI-II depict a distribution related to other studies among students with some students presenting symptoms of severe depression (Rotenstein et al. 2016). Various studies evaluate additional ways of treating depression and mental health issues apart from the pharmacological approach (Kvam et al. 2016; Prathikanti et al. 2017). Exercise compared to no treatment evoked a significant improvement in the well-being of the participants (Kvam et al. 2016). In our survey, a sports program that accommodates a full student schedule ranked third best, meaning that the awareness of the impact of physical exercise among students is present. Also, generally, a higher BDI-II correlated significantly with a higher level of application to many of the proposed support options. Hence, this is one big factor on which future support programs should be based.

A meta-analysis of the treatment of burnout among medical doctors indicates that supportive working conditions strengthen mental health even more than just individual therapy (Panagioti et al. 2017). Several factors prevent medical students from seeking mental health support, among them are the stigma surrounding it and the lack of time (Rodriguez et al. 2017). Still, surveys show that students report major improvements in their stress levels and coping abilities when they participate in an elective subject on coping strategies (Pereira et al. 2015).

The options proposed in the questionnaire only partly matched this survey population. A significant correlation with a specific option was the use of exercise/sports classes and relaxation techniques frequented by female students, which could be explained through the fact that female students tend to have stronger stress reactions (Pradhan et al. 2014). The frequency of diagnoses of mental problems is also higher among females (Picco et al. 2017).

\section{Strengths \& weaknesses}

One benefit of this survey is the fact that all students of the first 5 years of a medical school were assessed. The last (sixth) year is missing because students attend the practical year at various teaching hospitals outside the surveyed school. Still, surveys of such dimensions are rarely implemented (van Dijk et al. 2017).

Mostly, studies try to assess a pre-clinical year and a clinical year and then compare the results of these two years (Riemenschneider et al. 2016). Although this survey was carried out at one German medical school, it has to be stated that students are assigned to universities following a central selection process for all German medical schools. A strong selection bias can, therefore, not be assumed for the assessed students. This is also supported by the heterogeneity of the survey population (see Table 1).

What is also a clear advantage is not only the large population compared to other surveys, but also the objective approach to assessing students' opinions. Other surveys applied more subjective techniques (Kötter et al. 2015). We chose courses where a high response rate could be achieved. This resulted in varying survey dates throughout the semester. Students in their exam session might be under more stress 
and be more receptive toward a support program (Metzger et al. 2017). Nonetheless, this helped to achieve this large sample size of participating medical students.

\section{Implications for future research and practice}

According to this survey, only a few students would participate and take advantage of each option proposed. A large group of students ranked the support options between 3 and 5. This represents the target group of undecided students that might respond to implemented support. Further research should identify other options. One possibility could be to include fewer choices, which might result in clearer preferences.

Students tend to underestimate the effect of group treatment and overestimate their own ability to change lifestyle habits (Kendal and Diug 2017). Hence, it is also crucial to increase knowledge and awareness about coping strategies and support options. This results in encouraging medical students to seek assistance in order to strengthen their health before severe damage to their mental state has been done (Puthran et al. 2016; Hayes et al. 2017).

Surveys could be carried out at other German universities as well as universities outside of Germany to enhance the validity of the data from the University X for medical students (Lucchetti et al. 2018). This should also include students from other fields apart from medicine. In addition, cooperation between schools may be initiated in order to establish partnerships between students from different University departments. This would support medical students to widen their circle of study friends to include students from different subjects (van Ark and Wijnen-Meijer 2018). Qualitative research commenced in the form of interviews to identify support options named by the students themselves should be further pursued (Kötter et al. 2015).

\section{Conclusion}

Medical students want to be supported in their studies through a clear study structure. The intention of supporting medical students and taking their troubles seriously could already lead to a big difference for medical students. A bottoms-up methodology should dominate the development of measures in order to reach a majority of students. We need a support program that addresses students' wishes, not a program that is based on feasibility, staff passion or interest. If a preventive measure can save one medical student from a mental disease, encourage healthy behavior and raise their awareness for mental health, once they are a doctor themselves, they will pass their knowledge and experiences on to the general population.

Acknowledgements We thank all students for their time and participation in this survey and the Medical Faculty of the Martin Luther University HalleWittenbergfor their contribution of the survey material and premises.
Authors' contributions All authors contributed in writing the questionnaire and collecting the data. DS contributed a large part of his courses for carrying out the survey. KD supported the survey by distributing the questionnaire to students and editing the manuscript. LP was part of the team that initiated the survey. EE interpreted the collected data and contributed major parts of the manuscript. SW was the leader of the working group and a generous supporter in the statistical analysis. SF and TF were important contributors to the final form of the manuscript. All authors read and approved the final manuscript.

Funding Open Access funding enabled and oreganized by Project DEAL. The study was funded by general institutional funds.

Data availability The datasets used and analyzed during the current study are available from the corresponding author upon reasonable request.

\section{Compliance with ethical standards}

Ethics approval and consent to participate The Ethical Committee of the Martin Luther University Halle-Wittenberg approved of the study protocol on January 18, 2018 (2017-138). All survey participants received a cover letter explaining their full rights. Due to protection of personal data, the requirement for written consent was waved and no signature was obtained. The letter stated the right to withdraw from the survey at any time and explained about protection of personal data. It also included a statement that a withdrawal from the survey would not cause any personal or professional disadvantages. Blank lines were added in case students wished to state a reason for non-participation. We also encouraged students to take the questionnaire home to read it carefully and fill it in without anyone else present. We asked the students to return the questionnaires to specially secured boxes throughout campus.

Competing interests The authors declare that they have no competing interests.

Trial registrations The Ethical Committee of the Martin Luther University Halle-Wittenberg approved of the survey protocol on January 18, 2018 (2017-138).

Open Access This article is licensed under a Creative Commons Attribution 4.0 International License, which permits use, sharing, adaptation, distribution and reproduction in any medium or format, as long as you give appropriate credit to the original author(s) and the source, provide a link to the Creative Commons licence, and indicate if changes were made. The images or other third party material in this article are included in the article's Creative Commons licence, unless indicated otherwise in a credit line to the material. If material is not included in the article's Creative Commons licence and your intended use is not permitted by statutory regulation or exceeds the permitted use, you will need to obtain permission directly from the copyright holder. To view a copy of this licence, visit http://creativecommons.org/licenses/by/4.0/.

\section{References}

AlFaris EA, Naeem N, Irfan F, Qureshi R, van der Vleuten C (2014) Student centered curricular elements are associated with a healthier educational environment and lower depressive symptoms in medical students. BMC Med Educ 14. https://doi.org/10.1186/1472-692014-192

Brennan J, McGrady A, Lynch DJ, Schaefer P, Whearty K (2016) A stress management program for higher risk medical students: 
preliminary findings. Appl Psychophysiol Biofeedback 41(3):301305. https://doi.org/10.1007/s10484-016-9333-1

Dyrbye LN, Sciolla AF, Dekhtyar M, Rajasekaran S, Allgood JA, Rea M, Knight AP, Haywood A, Smith S, Stephens MB (2019) Medical school strategies to address student well-being: a national survey. Acad Med. https://doi.org/10.1097/ACM.0000000000002611

Hayes B, Prihodova L, Walsh G, Doyle F, Doherty S (2017) What's up doc? A national cross-sectional study of psychological wellbeing of hospital doctors in Ireland. BMJ Open 7(10). https://doi.org/10. 1136/bmjopen-2017-018023

Hippocrates of Cos (1923) The oath. In: Ancient medicine. Airs, waters, places. Epidemics 1 and 3. The oath. Precepts. Nutriment. Harvard University Press, Cambridge, MA, pp 298-302

Karay Y, Hallal H, Stosch C (2018) Research into finding a stable prognosis parameter for the detection of students in need of guidance realization of equal opportunities through a diversity-oriented study guidance. GMS J Med Educ 35(2). https://doi.org/10.3205/ zma001166

Kendal E, Diug B (eds) (2017) Teaching medicine and medical ethics using popular culture. Palgrave studies in science and popular culture. Springer, Cham

Kötter T, Pohontsch NJ, Voltmer E (2015) Stressors and starting points for health-promoting interventions in medical school from the students' perspective: a qualitative study. Perspect Med Educ 4(3): 128-135. https://doi.org/10.1007/s40037-015-0189-5

Kuhlmann SM, Bürger A, Esser G, Hammerle F (2015) A mindfulnessbased stress prevention training for medical students (MediMind): study protocol for a randomized controlled trial. Trials 16:40. https:// doi.org/10.1186/s13063-014-0533-9

Kvam S, Kleppe CL, Nordhus IH, Hovland A (2016) Exercise as a treatment for depression: a meta-analysis. J Affect Disord 202:67-86. https://doi.org/10.1016/j.jad.2016.03.063

Lamberti M, Napolitano F, Napolitano P, Arnese A, Panariello G, Di Giuseppe G (2017) Prevalence of alcohol use disorders among under- and post-graduate healthcare students in Italy. PLoS One 12(4):e0175719. https://doi.org/10.1371/journal.pone.0175719

Lehmann F, Lindeman K von, Klewer J, Kugler J (2014) BMI, physical inactivity, cigarette and alcohol consumption in female nursing students: a 5-year comparison. BMC Med Educ 14(82). https://doi.org/ $10.1186 / 1472-6920-14-82$

Lucchetti G, Furlan Damiano R, DiLalla LF, Lamas Granero Lucchetti A (2018) Cross-cultural differences in mental health, quality of life, empathy, and burnout between US and Brazilian medical students. Acad Psychiatry 42:62-67

Mangione S, Chakraborti C, Staltari G, Harrison R, Tunkel AR, Liou KT, Cerceo E, Voeller M, Bedwell WL, Fletcher K, Kahn MJ (2018) Medical Students' exposure to the humanities correlates with positive personal qualities and reduced burnout: a multi-institutional U.S. survey. J Gen Intern Med 33(5):628-634. https://doi.org/10. 1007/s11606-017-4275-8

Metzger IW, Blevins C, Calhoun CD, Ritchwood TD, Gilmore AK, Stewart R, Bountress KE (2017) An examination of the impact of maladaptive coping on the association between stressor type and alcohol use in college. J Am Coll Heal 65(8):534-541. https://doi. org/10.1080/07448481.2017.1351445

Oberg EB, Frank E (2009) Physicians' health practices strongly influence patient health practices. J R Coll Physicians Edinb 39(4):290-291. https://doi.org/10.4997/JRCPE.2009.422

Panagioti M, Panagopoulou E, Bower P, Lewith G, Kontopantelis E, Chew-Graham C, Dawson S, van Marwijk H, Geraghty K, Esmail A (2017) Controlled interventions to reduce burnout in physicians: a systematic review and meta-analysis. JAMA Intern Med 177(2): 195-205. https://doi.org/10.1001/jamainternmed.2016.7674

Pereira MAD, Barbosa MA, de Rezende JC, Damiano RF (2015) Medical student stress: an elective course as a possibility of help. BMC Res Notes 8:430. https://doi.org/10.1186/s13104-015-1399-y

Picco L, Subramaniam M, Abdin E, Vaingankar JA, Chong SA (2017) Gender differences in major depressive disorder: findings from the Singapore mental health study. Singap Med J 58(11):649-655. https://doi.org/10.11622/smedj.2016144

Pradhan G, Mendinca NL, Kar M (2014) Evaluation of examination stress and its effect on cognitive function among first year medical students. J Clin Diagn Res 8(8):05-07. https://doi.org/10.7860/ JCDR/2014/9014.4680

Prathikanti S, Rivera R, Cochran A, Tungol JG, Fayazmanesh N, Weinmann E (2017) Treating major depression with yoga: A prospective, randomized, controlled pilot trial. PLoS ONE 12(3). https://doi.org/10.1371/journal.pone.0173869

Puthran R, Zhang MWB, Tam WW, Ho RC (2016) Prevalence of depression amongst medical students: a meta-analysis. Med Educ 50(4):456-468. https://doi.org/10.1111/medu. 12962

Riemenschneider H, Balázs P, Balogh E, Bartels A, Bergmann A, Cseh K, Faubl N, Füzesi Z, Horváth F, Kiss I, Schelling J, Terebessy A, Voigt K (2016) Do socio-cultural factors influence medical students' health status and health-promoting behaviors? A crosssectional multicenter study in Germany and Hungary. BMC Public Health 16(576). https://doi.org/10.1186/s12889-016-3228-1

Rodriguez ML, Corse AK, Rosen LD (2017) Mental Health Services Use Among Medical Students: Perceived Stigma and Barriers to Care. Medical Science Educator 27(2):1-6. https://doi.org/10.1007/ s40670-017-0392-6

Rotenstein LS, Ramos MA, Torre M, Segal JB, Peluso MJ, Guille C, Sen S, Mata DA (2016) Prevalence of depression, depressive symptoms, and suicidal ideation among medical students: a systematic review and meta-analysis. JAMA 316(21):2214-2236. https://doi.org/10. 1001/jama.2016.17324

Schmidt M, Hansson E (2018) Doctoral students' well-being: a literature review. Int J Qual Stud Health Well-being 13(1):1508171. https:// doi.org/10.1080/17482631.2018.1508171

Terebessy A, Czeglédi E, Balla BC, Horváth F, Balázs P (2016) Medical students' health behaviour and self-reported mental health status by their country of origin: A cross-sectional study. BMC Psychiatry 16(171). https://doi.org/10.1186/s12888-016-0884-8

van Ark AE, Wijnen-Meijer M (2018) "Doctor jazz": lessons that medical professionals can learn from jazz musicians. Med Teach 48:1-6. https://doi.org/10.1080/0142159X.2018.1461205

van Dijk I, Lucassen PLBJ, van Weel C, Speckens AEM (2017) A crosssectional examination of psychological distress, positive mental health and their predictors in medical students in their clinical clerkships. BMC Med Educ 17(219). https://doi.org/10.1186/s12909017-1035-8

Wasson LT, Cusmano A, Meli L, Louh I, Falzon L, Hampsey M, Young G, Shaffer J, Davidson KW (2016) Association between learning environment interventions and medical student well-being: a systematic review. JAMA 316(21):2237-2252. https://doi.org/10. 1001/jama.2016.17573

Williams D, Tricomi G, Gupta J, Janise A (2015) Efficacy of burnout interventions in the medical education pipeline. Acad Psychiatry 39: 47-54. https://doi.org/10.1007/s40596-014-0197-5

Publisher's note Springer Nature remains neutral with regard to jurisdictional claims in published maps and institutional affiliations. 